\title{
Behaviour of Medical Students when Faced with Ethical Dilemmas in Research
}

\author{
Edussuriya Deepthi ${ }^{1}$, Samaranayake Achini ${ }^{2}$ \\ Department of Forensic Medicine, Faculty of Medicine, University of Peradeniya, Sri Lanka
}

\begin{abstract}
A study was conducted to determine the course of action opted for by medical students when faced with ethical dilemmas in research. A questionnaire with 10 scenarios related to ethical dilemmas related to research was administered to randomly selected $4^{\text {th }}$ year medical students who had completed all components of the training in research ethics and had completed an undergraduate research group project. The results revealed that students had doubts and inaccuracies of knowledge regarding some basic aspects of research, in spite of repeated exposure to instruction on research ethics and having completed an undergraduate research project of their own. This underscores the importance of structuring research ethics curricular to ensure that students practice what they learn. Therefore, it is not adequate to merely develop the student's knowledge and skills in ethics related to research by conducting lectures and research projects. It is necessary like in the teaching of other aspects of medical ethics to employ methods to ensure a change in attitude of students.
\end{abstract}

Keywords: Research Ethics, Medical students, Authorship

\section{Introduction}

Just as we are conscious of ethics in the practice of our own specialties, it is of paramount importance that research is conducted within an ethical framework. A breach of research ethics is a disgrace to the institution, the researcher and the research community as whole.

Many ethical issues relating to research are reported in the literature. Issues regarding authorship[1], publication(2), conduct of research[3] and data sharing[4] have been constantly discussed and debated about by researchers.

Medical research is a significant component of the undergraduate curricula in most medical faculties worldwide. At the Faculty of Medicine, University of Peradeniya, Sri Lanka, the students complete an undergraduate research project under the Communication Learning and Research stream. The students do a literature search, develop a proposal, obtain ethical clearance, collect data, analyse and write a report during a period of 2 years (from $2^{\text {nd }}$ to $4^{\text {th }}$ years). This is supervised by academic staff members of the faculty of medicine. The project is subsequently evaluated by two examiners independently and a viva voce is conducted. Didactic lectures on research ethics are conducted for the students during this period which is approximately of 2-4 hrs. duration. This is assessed by essay or structured questions.

The basis for the study was a presumption that despite lectures, evaluations and an opportunity to practice, the students are unclear as to the best course of action to take when actually faced with ethical dilemmas related to research. The literature too revealed evidence of unethical conduct in certain aspects of research such as plagiarism, duplicate publication etc. worldwide $[2,3,4,5]$. Such information regarding the behaviour of students when faced with ethical dilemmas in research would be useful in structuring curricula and for supervisors of research projects in order to guide students to make ethically correct decisions.

\section{Objective}

To determine the course of action opted for by medical students when faced with ethical dilemmas in research.

\section{Methods}

A questionnaire was formulated to include 10 scenarios which illustrate ethical dilemmas that are commonly encountered when conducting research. Possible courses of action were included as options. The questionnaire was pretested, modified and administered to 34 randomly selected $4^{\text {th }}$ year medical students who had completed all components of the training in research ethics, and had done an undergraduate research group project. Participation was voluntary. Participants ${ }^{\text {ee }}$ responses were analysed using Microsoft Excel.

\section{Results}

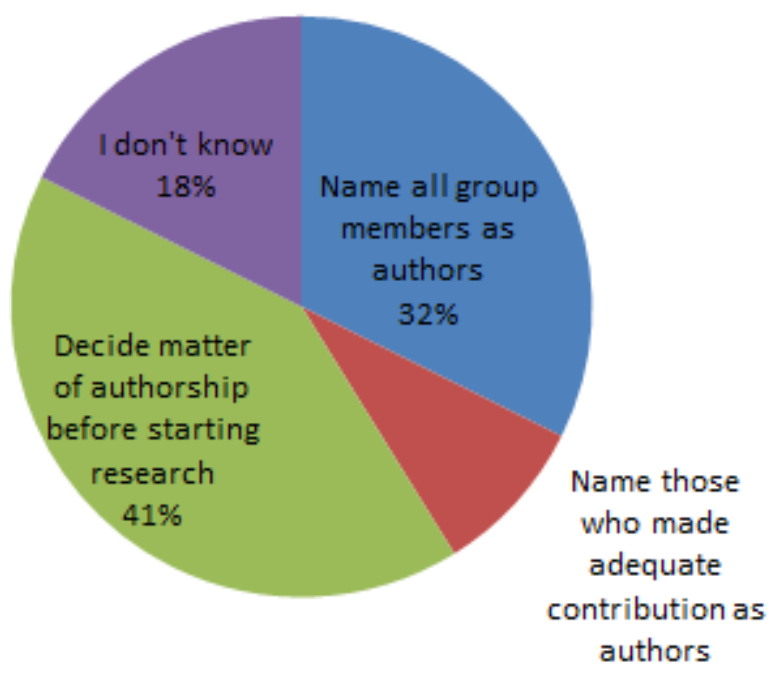

Figure 1: Students ${ }^{\text {ee }}$ views regarding assigning authorship to members of the research team who did not contribute adequately to the research 


\section{International Journal of Science and Research (IJSR) \\ ISSN (Online): 2319-7064}

Index Copernicus Value (2013): 6.14 | Impact Factor (2014): 5.611

\section{Inference}

$32 \%$ responded that they will name all group members as authors regardless of their extent of contribution, while $18 \%$ did not know which course of action they should take. $41 \%$ declared that they will discuss who would get authorship if the research is published before the commencement of the research project, while $9 \%$ responded that they will name only those who made adequate contribution to the research as authors.

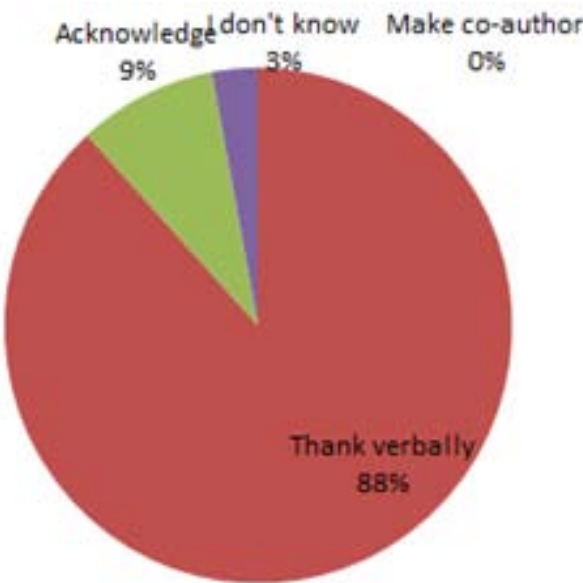

Figure 2: Students ${ }^{\text {ee }}$ views regarding assigning authorship to a colleague who takes on routine ward duties so that the researcher can devote more time for research.

\section{Inference}

$88 \%$ declared they will thank the peer verbally. While $9 \%$ said they will mention his contribution under their research report's acknowledgements. None of the participants chose the option of ,awardinge authorship to the peer.

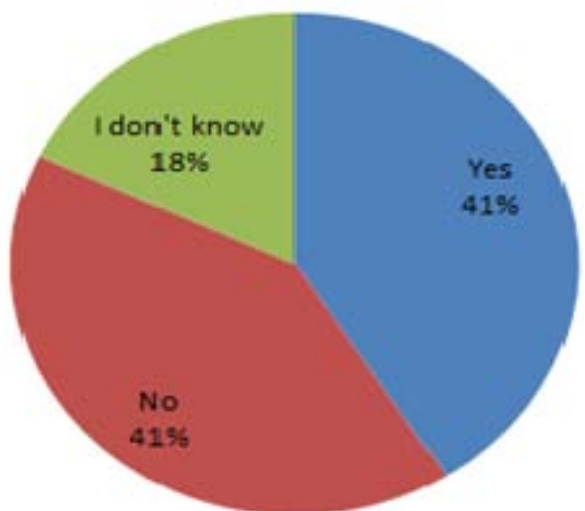

Figure 3: Students ${ }^{\text {ee }}$ views regarding whether they would assign authorship to a superior whose patients were used for the research

\section{Inference}

$41 \%$ of respondents declared they will name the superior as an author. Reasons for gifting authorship were as follows: to help the research gain recognition (37\%), obliged to as he is the superior $(25 \%)$, obliged as using his patients $(25 \%)$, does not like to displease (13\%)

\section{Issues related to publication}

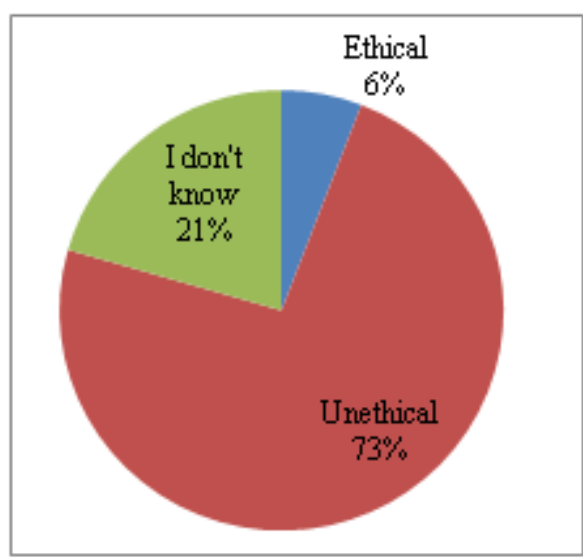

Figure 4: Students ${ }^{\text {ee }}$ views regarding dual submission

\section{Inference}

Only $6 \%$ of participants responded in favour of dual submission. $73 \%$ declared that they will withdraw the article and then submit it to a second journal.

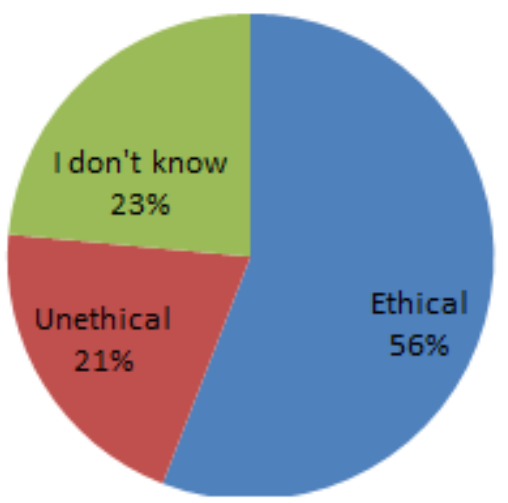

Figure 5: Students ${ }^{\text {ee }}$ views regarding piecemeal publication

\section{Inference}

$56 \%$ did not think that piecemeal publication was unethical. However $21 \%$ declared that this was unethical.

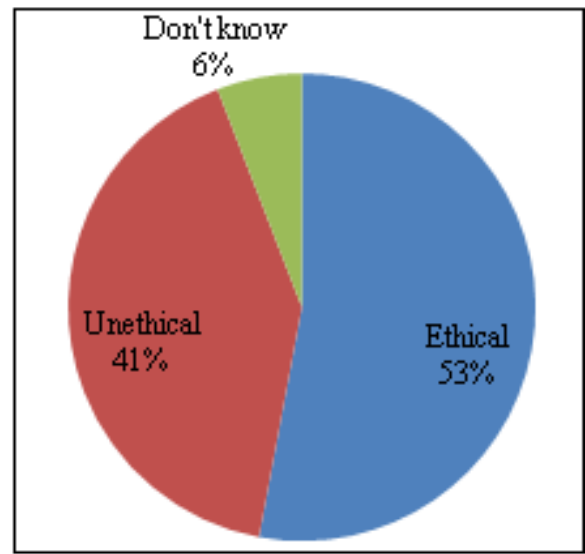

Figure 6: Students ${ }^{\text {ee }}$ views regarding referring to abstracts instead of full papers in research

Inference

$53 \%$ responded that they may use information from abstracts for their study while $41 \%$ Said they would only obtain information from full articles. 


\section{International Journal of Science and Research (IJSR) \\ ISSN (Online): 2319-7064}

Index Copernicus Value (2013): 6.14 | Impact Factor (2014): 5.611

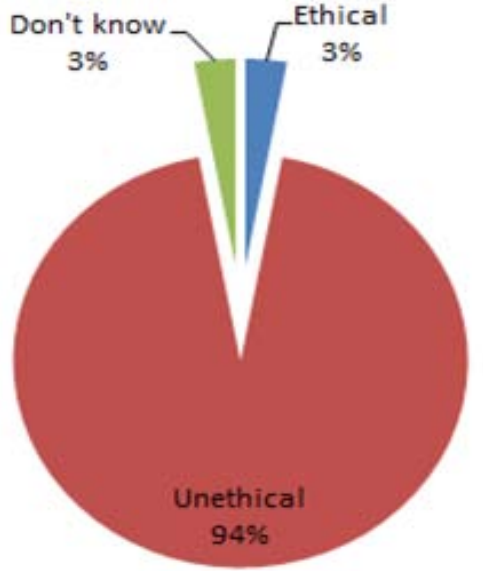

Figure 7: Students ${ }^{\text {ee }}$ views regarding the use of vulnerable groups as research subjects

\section{Inference}

In a situation where participants were being recruited by the treating physician $94 \%$ responded that this was unethical in spite of consent as ,the patients may feel obligated to participate in the research.

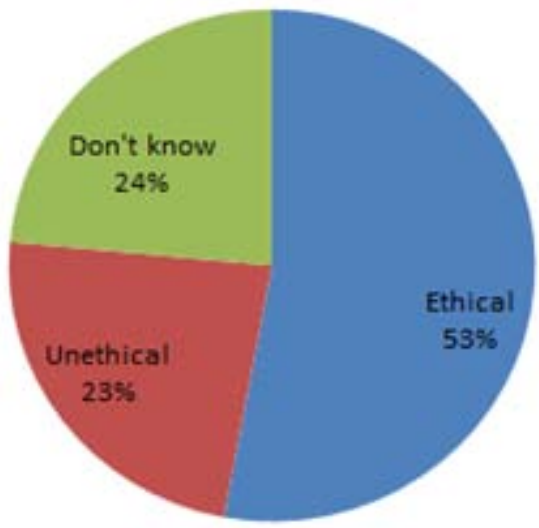

Figure 8: Students ${ }^{\text {ee }}$ views regarding copying the research methodology from another article

\section{Inference}

$53 \%$ of participants responded that it was ethically correct to adopt a methodology used by another researcher provided that the original researchers were duly credited, $23 \%$ thought it was unethical while $24 \%$ did not know the correct course of action.

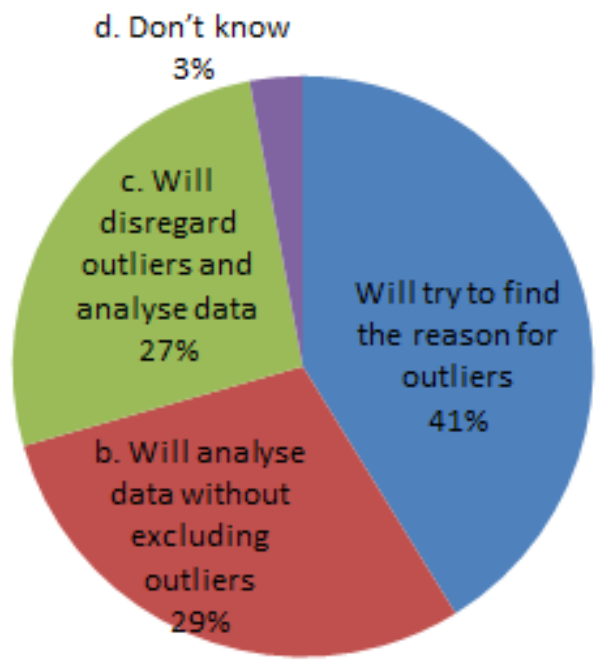

Figure 9: Students ${ }^{\text {ee }}$ views regarding outliers in data analysis

\section{Inference}

In the case of data analysis, $70 \%$ responded favourably, $41 \%$ saying they will try to find a reason for outliers, and $29 \%$ saying they will include outliers in the data analysis. However $27 \%$ claimed they will disregard outliers.

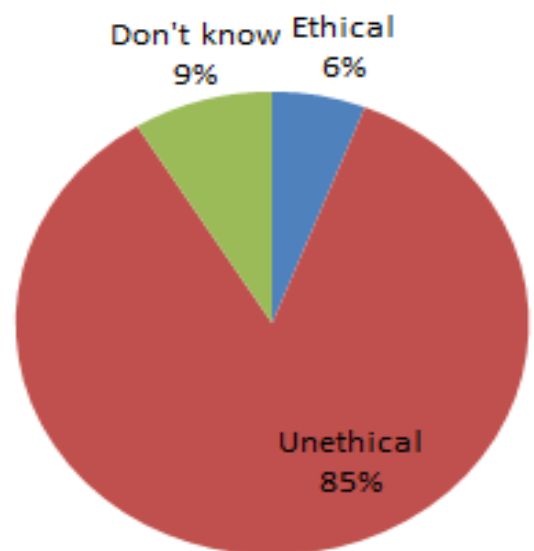

Figure 10: Students ${ }^{\text {ee }}$ views regarding sharing of data with another research group

Inference

$85 \%$ responded that it was unethical for one group of researchers to share data with another research group.

\section{Discussion}

This study focuses on three main aspects of research ethics: assignment of authorship, conduct of research including consent, data analysis, data sharing and research report writing and publication.

Ethical misconduct in research has frequently been reported in the literature. Eighteen percent of medical, dental and veterinary students enrolled in research fellowships admitted that authorship was wrongly assigned during their researches [6]. This compares well with the findings of our study which revealed that when assigning authorship to research team members half the students did not know the appropriate course of action to take. This is significant in the light of their background and training. Even though a significant proportion claimed that a decision on authorship would be taken prior to commencement of the research only a very small proportion agreed that authorship should be given to only those who contributed. Furthermore, it is important to note that the students were less clear when assigning authorship to a superior. It appeared that factors such as obligation, recognition etc. came into play during the process. This clearly illustrates the need not only to provide adequate knowledge during the training but also ensure the development of related values. This is further illustrated by the work of Karani[6] and Bhopal[7]where it was seen that researchers had adequate knowledge about the concept of authorship, but nevertheless assigned authorship incorrectly when conducting research.

In terms of support provided for research activities, it appears that students have a clear idea on how to determine at what level the assistance needs to be recognised. However 


\section{International Journal of Science and Research (IJSR) \\ ISSN (Online): 2319-7064}

Index Copernicus Value (2013): 6.14 | Impact Factor (2014): 5.611

there appeared to be some confusion when distinguishing between assigning authorship and providing acknowledgement.

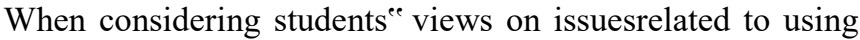
vulnerable groups as research subjects a significant majority responded that this was unethical in spite of consent as ,the participants may feel obligated to participate in the research ${ }^{\text {ee }}$. This implies that the students have favourable attitudes about the concept of vulnerable parties. This is in contrast to a study conducted by Haqueet. Alwhere it was revealed that $65 \%$ of researchers who participated had no knowledge or partial knowledge regarding vulnerable groups [8].

In the case of data analysis where outliers have been identified in a data set, using information from abstracts in writing research papers and whereethics of reproducing the research methodology from another study were consideredthe opinion regarding the best course of action was diverse. This highlights the need to emphasise such issues during the training of students.

When questioned about submitting the same article to two journals simultaneously, even though a majority of students were aware of the ethics of dual submission, over one fourth of the group was unaware of the correct course of action. More than half the group did not know that piecemeal publication was unethical while almost a quarter were not sure of the ethical aspects of this.

\section{Conclusion}

It is ironic that students had doubts and inaccuracies of knowledge regarding some basic aspects of research, in spite of repeated exposure to instruction on research ethics and having completed an undergraduate research project of their own. The students appeared to be fairly clear on assigning authorship where peers are involved but seemed less confident where a superior was involved. They need to be educated in piecemeal publication, using information from abstracts, reproducing research methodology from other studies and trimming outliers.

This underscores the importance of structuring research ethics curricular to ensure that students practice what they learn.

\section{Recommendations}

It is not adequate to merely develop the student"s knowledge and skills in ethics related to research by conducting lectures and research projects. It is necessary like in the teaching of other aspects of medical ethics to employ methods to ensure a change in attitude of students.

\section{References}

[1] Caruth, Gail D, “Academic Dishonesty: The Question of Authorship" .International Journal of Scholarly Academic Intellectual Diversity Vol.16 No.1, 2014. [Online] Available from

http://www.nationalforum.com/Electronic\%20Journal\%2
0Volumes/Caruth,\%20Gail\%20D\%20Academic\%20Dish onesty $\% 20$ -

\%20The $\% 20$ Question $\% 20$ of $\% 20$ Authorship \%20IJSAID $\% 20 \mathrm{~V} 16 \% 20 \mathrm{~N} 1 \% 202014 . \mathrm{pdf}$, Accessed 28th Oct 2015

[2] Amos, Kathleen A. "The ethics of scholarly publishing: exploring differences in plagiarism and duplicate publication across nations." Journal of the Medical Library Association: JMLA 102.2 (2014): 87.

[3] Marusic A, Katvic V., Marusic M. "Dealing with Scientific Misconduct in the Future: Role of editors and journals in detecting and preventing scientific misconduct: strengths, weaknesses, opportunities and threat "Med Law (2007) 26:545-566 Medicine 545

[4] Reidpath, D. D. and Allotey, P. A. (2001), Data Sharing in Medical Research: An Empirical Investigation. Bioethics, 15: 125-134. doi: 10.1111/1467-8519.00220

[5] Bilić-Zulle L, Frković V, Turk T, Azman J, Petrovecki M., "Prevalence of plagiarism among medical students". Croatian Medical Journal 2005 Feb;46[1]:126-31. [Online] Available from http://www.ncbi.nlm.nih.gov/pubmed/15726686 Accessed 28th Oct. 2015

[6] Karani, Reena et al. "Medical studentse experiences with authorship in biomedical research: a national survey." Academic Medicine 88.3 (2013): 364-368.

[7] Bhopal, Raj et al. "The vexed question of authorship: views of researchers in a British medical faculty." BMJ 314.7086 (1997): 1009.

[8] Haque, MJ. "Research on Vulnerable Groups: The Medical Researcher's view." The Journal of Teacherse Association RMC Rajshahi, Vol.18 No.1, June 2005. [Online] Available from http://www.banglajol.info/index.php/TAJ/article/downloa d/3303/2768, Accessed on 28th Oct 2015

\section{Author Profile}

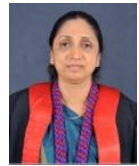

Deepthi Edussuriya (MBBS, Mphil, $\mathrm{PhD}$ )is a senior lecturer at the Department of Forensic Medicine, Faculty of Medicine, University of Peradeniya, Sri Lanka. She has a special interest in medical education.

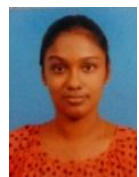

Achini Samaranayake(MBBS) currently works as a Temporary Lecturer at the Department of Forensic Medicine, Faculty of Medicine, University of Peradeniya, Sri Lanka. 